\title{
External validation of a predictive model of acute postoperative pain at home after ambulatory surgery
}

\author{
Björn Stessel1,2; Elbert A.Joosten 2;. Fiddelers²; Sander M.J. van Kuijk³; \\ Wolfgang F.F.A. Buhre ${ }^{2}$; Hans-Fritz Gramke ${ }^{2}$ \\ ${ }^{1}$ Department of Anesthesiology and Pain Medicine, Jessa Hospital, Hasselt, Belgium
} ${ }^{2}$ Department of Anesthesiology and Pain Medicine, Maastricht University Medical Center+, Maastricht, the Netherlands ${ }^{3}$ Department of Clinical Epidemiology and Medical Technology Assessment, Maastricht University

Background and Goal of Study: A prediction model to pre-operatively detect those patients at risk for moderate

to severe acute postoperative pain (APSP) after ambulatory surgery has been described by Gramke et al. in $2009^{1}$. Before considering use and implementation of this prediction model, the generalizability of the model needs to be evaluated in a new population by external validation. Hence, the aim of our study was to externally validate this model.

Materials and methods: Elective patients scheduled for day surgery were prospectively enrolled from November 2008 to April 2010. Outcome parameters were measured by using questionnaire packages at two time points: one week preoperatively and four days postoperatively. For each individual in our cohort, the predicted probability of

moderate to severe APSP, defined as NRS > 4, was

computed using the regression coefficients (i.e. the

natural logarithm of the odds ratios) of the model presented by Gramke et al. in 2009. Model discrimination was tested by determining the area under the receiver operating characteristic curve (AUC). Model calibration

was tested by an inspection of the calibration plot.

Results and discussion: A total of 1118 patients were included. Overall, the baseline characteristics of the derivation and the validation cohorts were similar (table 1). The AUC for the original model was 0.82 in the derivation dataset and 0.71 in our validation dataset. The calibration plot of this model shows a risk prediction that is too extreme, i.e. an underestimation of the predicted low risks and a distinct overestimation of the predicted high risks (Figure 1).
Table 1: Baseline patient characteristics. NRS = Numeric Rating Scale

\begin{tabular}{|l|c|c|}
\hline Age & $\begin{array}{c}\text { N (\%) / Mean (SD) } \\
\text { Stessel et al. }\end{array}$ & $\begin{array}{c}\text { N (\%) / Mean (SD) } \\
\text { Gramke et al. } \\
\text { (2009) }\end{array}$ \\
\hline$<45$ years & $52.5(14.3)$ & $49.3(16.9)$ \\
\hline $45 . \quad-59$ years & $340(30)$ & $240(37)$ \\
\hline$>59$ years & $387(35)$ & $232(36)$ \\
\hline Gender & $391(35)$ & $176(27)$ \\
\hline Male & & \\
\hline Female & $505(45)$ & $281(43)$ \\
\hline Educational background & $613(55)$ & $367(57)$ \\
\hline Ilementary school & $356(32)$ & \\
\hline Intermediate & $430(38)$ & $221(34)$ \\
\hline Higher degree, university & $319(29)$ & $170(26)$ \\
\hline Information missing & $13(1)$ & $10(2)$ \\
\hline Preoperative pain & & \\
\hline VAS > 10mm/NRS $>1$ & $592(53)$ & $138(21)$ \\
\hline VAS > 30mm/NRS $>3$ & $424(38)$ & $71(11)$ \\
\hline Anticipated postoperative pain & & \\
\hline level (type of surgery) & & \\
\hline Minor & $647(58)$ & $452(70)$ \\
\hline Intermediate & $469(42)$ & $196(30)$ \\
\hline Type of anesthesia & & \\
\hline General & & $400(62)$ \\
\hline Regional & $933(84)$ & $248(38)$ \\
\hline
\end{tabular}

Figure 1: Calibration line of the prediction model of Gramke et al. in the validation cohort

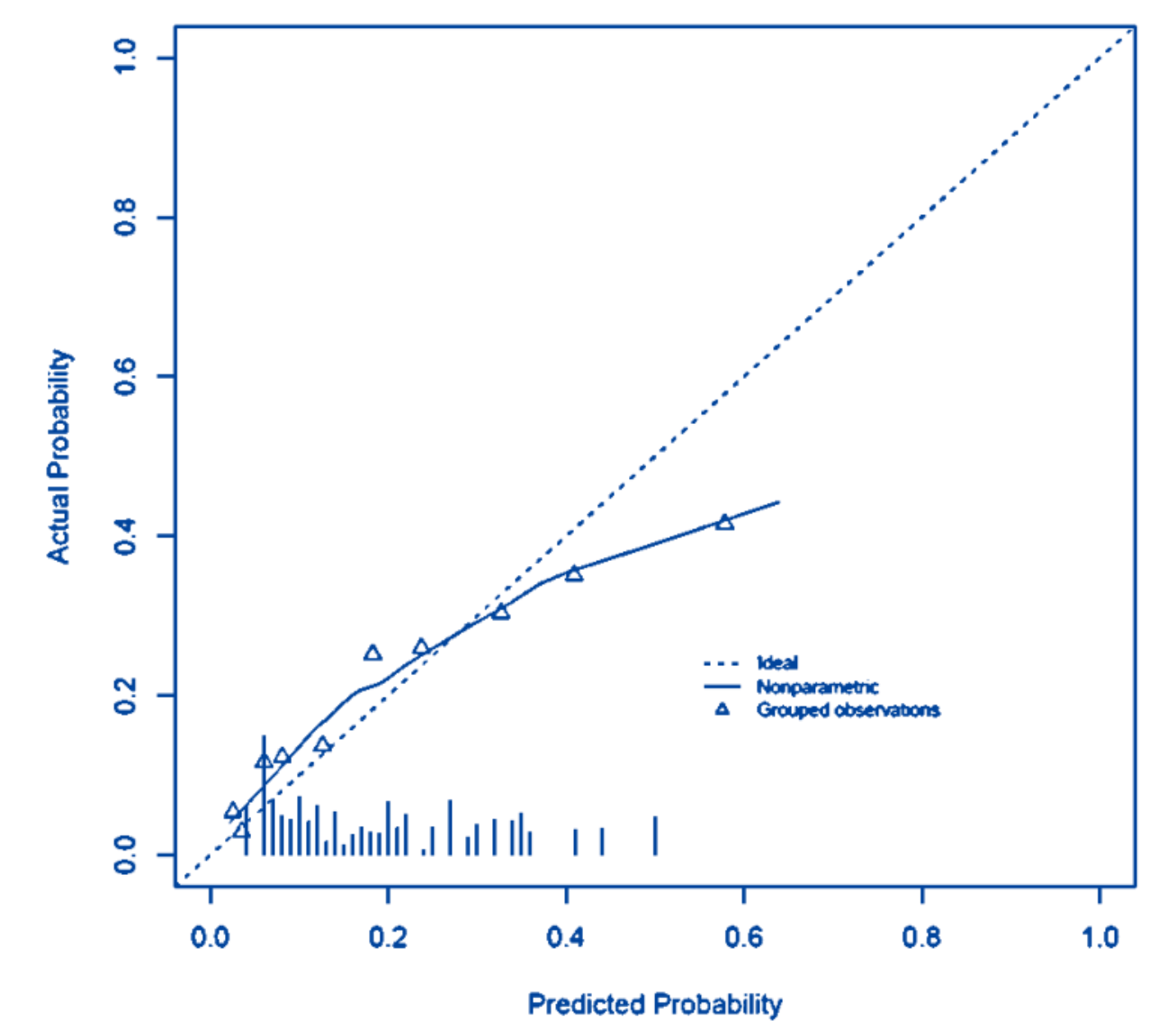

Conclusion: We could not externally validate the use of the prediction model of Gramke et al.2009 on our cohort of outpatients since both discrimination and calibration were less than expected. 